\title{
POSISI SEKTOR PERIKANAN DAN PARIWISATA BAHARI DALAM PETA KETERKAITAN EKONOMI SULAWESI UTARA: Analisis Pendekatan Input-Output
}

\author{
Lindawati, Sastrawidjaja dan Tajerin ${ }^{1}$ \\ ${ }^{1}$ Peneliti pada Balai Besar Riset Sosial Ekonomi Kelautan dan Perikanan \\ JI. KS Tubun Petamburan VI Jakarta 10260. \\ Telp. (021)53650162, Fax. (021)53650159 \\ Diterima 15 Pebruari 2010 - Disetujui 26 Juni 2010
}

\begin{abstract}
ABSTRAK
Pembangunan sektor perikanan dan pariwisata bahari mempunyai peranan yang penting dalam perekonomian Sulawesi Utara. Hal tersebut dapat dilihat dari keterkaitan sektor perikanan dan pariwisata bahari tersebut dalam perekonomian Sulawesi Utara. Tulisan ini membahas posisi sektor perikanan dan pariwisata bahari dalam peta perekonomian provinsi Sulawesi Utara. Data yang digunakan dalam kajian ini adalah data sekunder dari Tabel Input-Output Tahun 2005, dan dianalisis dengan menggunakan pendekatan model Input-Output melalui metode analisis keterkaitan. Hasil analisis menunjukkan bahwa pada tahun 2005 secara rata-rata keterkaitan sektor perikanan dan pariwisata bahari dalam perekonomian Sulawesi Utara termasuk dalam kategori kuat dan termasuk ke dalam kelompok sektor andalan/unggulan. Hal ini ditunjukkan dengan indeks keterkaitan ke belakang dan ke depan khususnya untuk kelompok perikanan sekunder (sektor industri pengolahan dan pengawetan ikan) dan sektor pariwisata bahari yang lebih besar dari rata-rata keseluruhan sektor dalam perekonomian Sulawesi Utara.
\end{abstract}

Kata kunci : perikanan, perekonomian, model input-output

\section{Abstract: Fisheries and Marine Tourism Position Sectors in the Economy Linkages Map of North Sulawesi Province: An Input-Output Approach. By: Lindawati, Sastrawidjaja and Tajerin}

Fisheries and marine tourism sectors play important roles in North Sulawesi economy. The linkage between fisheries and marine tourism sector indicate these roles. This paper discusses and assesses position fisheries and marine tourism sector in the economy of North Sulawesi Province. This research uses secondary data from the Input-Output Table 2005. Through linkage analytical method. Results of this research show that there was a strong linkage between fisheries and marine tourism sectors in 2005 in North Sulawesi economy. Index of backward and forward linkages provides evidence of this strong connections, especially for secondary fishery activities (processing and preserving industries) and marine tourism sectors. The linkages are also higher than other sectors in North Sulawesi economy.

Keywords: fishery, economy, input-output model 


\section{PENDAHULUAN}

Berdasarkan klasifikasi PKSPL-IPB, terdapat tujuh sektor besar yang termasuk dalam bidang kelautan, yaitu: (1) Perikanan; (2) Pertambangan laut; (3) Industri hasil laut dan perikanan; (4) Angkutan laut; (5) Pariwisata Bahari; (6) Bangunan kelautan dan perikanan; dan (7) Jasa kelautan lainnya (Kusumastanto, 2002).

Sektor perikanan dan sektor pariwisata bahari merupakan dua sektor unggulan dari bidang kelautan Indonesia. Dari Tabel 1 dapat diketahui bahwa peran kedua sektor tersebut dalam perekonomian nasional menunjukkan kecenderungan yang semakin meningkat meskipun masih bersifat fluktuatif dengan persentase yang relatif belum tergolong besar.

Dalam realitasnya, peran kedua sektor tersebut (perikanan dan pariwisata bahari) sangat ditentukan oleh kemampuan masingmasing daerah dalam mengelola sumber daya di kedua sektor tersebut. Salah satu daerah di Indonesia yang memiliki prospek pemanfaatan ekonomi sumber daya perikanan dan pariwisata bahari yang cukup potensial adalah Provinsi Sulawesi Utara. Provinsi ini memiliki perairan yang cukup luas dengan potensi perikanan yang besar dengan luas sekitar $\pm 110.000 \mathrm{Km}^{2}$ dengan panjang garis pantai $\pm 1.740 \mathrm{Km}$. Selain itu, Sulawesi Utara juga merupakan salah satu provinsi yang merupakan pusat pengembangan industri pariwisata dan industri perikanan, baik untuk perikanan darat maupun perikanan laut. Dengan potensi yang dimiliki tersebut masih terbuka peluang untuk meningkatkan produksi di sektor perikanan, baik untuk memenuhi kebutuhan pasar domestik maupun pasar luar negeri yang secara tidak langsung akan membantu dalam meningkatkan perekonomian Sulawesi Utara khususnya dan perekonomian Indonesia pada umumnya.

Untuk itu, program pengembangan perikanan dan pariwisata baharí di Sulawesi Utara merupakan respon positif yang dapat diambil dalam rangka menjawab kebutuhan

Tabel 1. Distribusi dan Kontribusi Produk Domestik Bruto (PDB) di Sektor Kelautan Tahun 1995-2002 Atas Harga Konstan

Table 1. Distribution and Contribution of Gross Domestic Product (PDB) in the Marine Sector Years 1995-2002 at Constant Price

\begin{tabular}{|c|c|c|c|c|c|c|c|c|c|}
\hline \multirow{2}{*}{ No. } & \multirow{2}{*}{$\begin{array}{l}\text { Sub Sektor Kelautan/ } \\
\text { Sub Sector Marine }\end{array}$} & \multicolumn{8}{|c|}{$\begin{array}{l}\text { Prosentase (\%) Produk Domestik Bruto/ } \\
\text { Percentage (\%) Gross Domestic Product }\end{array}$} \\
\hline & & 1995 & 1996 & 1997 & 1998 & 1999 & 2000 & 2001 & 2002 \\
\hline 1 & Perikanan/Fisheries & 1,54 & 1,51 & 1,99 & 2,45 & 2,31 & 2,29 & 2,30 & 2,69 \\
\hline \multirow{2}{*}{$\begin{array}{l}2 \\
3\end{array}$} & Pertambangan/Mining & 4,16 & 4,01 & 3,85 & 4,65 & 7,23 & 10,02 & 9,17 & 9,38 \\
\hline & $\begin{array}{l}\text { Industri Maritim/Maritime } \\
\text { Industries }\end{array}$ & 2,74 & 2,87 & 3,97 & 3,48 & 3,38 & 3,32 & 3,77 & 3,11 \\
\hline 4 & $\begin{array}{l}\text { Angkutan Laut/ Sea } \\
\text { Transportation }\end{array}$ & 0,83 & 0,86 & 1,08 & 1,55 & 1,51 & 1,58 & 1,46 & 1,64 \\
\hline 5 & $\begin{array}{l}\text { Pariwisata Bahari/Maritime } \\
\text { Tourism }\end{array}$ & 0,79 & 0,73 & 0,86 & 2,21 & 1,53 & 1,44 & 1,61 & 2,24 \\
\hline 6 & $\begin{array}{l}\text { Bangunan Kelautan/Marine } \\
\text { Building }\end{array}$ & 0,74 & 0,65 & 1,08 & 1,50 & 1,22 & 1,08 & 1,10 & 1,34 \\
\hline & $\begin{array}{l}\text { Jasa kelautan Lainnya/Other } \\
\text { Marine Service }\end{array}$ & 0,97 & 0,78 & 1,56 & 1,19 & 1,15 & 1,10 & 1,09 & 1,23 \\
\hline \multicolumn{2}{|c|}{$\begin{array}{l}\text { Kontribusi PDB Sektor Kelautan } \\
\text { terhadap PDB } \\
\text { Nasional/Contribution PDB Marine } \\
\text { Sector to PDB National }\end{array}$} & 12,37 & 11,41 & 14,39 & 18,13 & 18,63 & 20,05 & 20,50 & 22,63 \\
\hline
\end{tabular}

Sumber: Data BPS diolah berdasarkan Tabel Input-Output/

Sources :Processing Data BPS of Input Output Table 
pemerintah yang terkait dengan percepatan pembangunan di sektor kelautan dan perikanan. Diharapkan melalui program tersebut, kegiatan perekonomian di Sulawesi Utara dapat lebih ditingkatkan lagi, terutama melalui upaya memperbesar derajat keterkaitan ekonomi baik dari sektor perikanan kepada sektor lainnya maupun sebaliknya. Dengan kata lain terjadi peningkatan derajat keterkaitan ke belakang (backward linkage) maupun keterkaitan ekonomi ke depan (forward linkage) antara sektor perikanan dan pariwisata baharí dengan sektor lain dalam perekonomian Sulawesi Utara. Hal ini terkait dengan besarnya peranan yang dapat diberikan oleh sektor-sektor tersebut dalam perekonomian Sulawesi Utara secara keseluruhan.

Oleh karena itu, kajian ini dilakukan untuk mengetahui sejauhmana posisi sektor perikanan dan pariwisata baharí dalam peta keterkaitan ekonomi di Provinsi Sulawesi Utara. Hasil kajian ini diharapkan dapat bermanfaat sebagai bahan masukan bagi penentu kebijakan dalam meningkatkan efektifitas program revitalisasi sektor perikanan dan pariwisata baharí melalui penguatan derajat keterkaitannya dengan sektor lain dalam perekonomian di Sulawesi Utara.

\section{METODOLOGI PENELITIAN}

\section{Landasan Teoritis}

Menurut Nazara (1997), tabel Input Output (I-O) adalah suatu tabel berbaris matriks yang disusun untuk menyajikan gambaran tentang hubungan timbal balik dan saling keterkaitan antara satuan kegiatan (sektor) dalam perekonomian. Dalam menyusun suatu Tabel I-O yang bersifat statis dan terbuka, transaksi-transaksi yang digunakan dalam penyusunan tabel input-output harus memenuhi tiga asumsi atau prinsip dasar, yaitu:

a. Keseragaman (homogenity), yaitu asumsi bahwa setiap sektor hanya memproduksi satu jenis output (barang dan jasa) dengan struktur input tunggal (seragam) dan tidak ada substitusi otomatis antar output dari sektor yang berbeda.

b. Kesebandingan (proportionality), yaitu asumsi bahwa kenaikan penggunaan input oleh suatu sektor akan sebanding dengan kenaikkan output yang dihasilkan.

c. Penjumlahan (additivity), yaitu asumsi bahwa jumlah pengaruh kegiatan produksi di berbagai sektor merupakan penjumlahan dari pengaruh pada masingmasing sektor tersebut.

Untuk memperoleh gambaran tentang bagaimana suatu tabel I-O disusun, maka pada Tabel 2 disajikan contoh tabel I-O untuk sistem perekonomian yang terdiri dari n sektor produksi, yaitu sektor 1, 2 hingga sektor $n$. Isian sepanjang baris pada Tabel 2 memperlihatkan bagaimana output dari suatu sektor dialokasikan, yaitu sebagian untuk memenuhi permintaan antara dan sebagian lainnya untuk memenuhi permintaan akhir. Sedangkan isian sepanjang kolomnya menunjukkan pemakaian input antara dan input primer oleh suatu sektor.

Berdasarkan cara pengisian angkaangka ke dalam sistem matriks, maka dapat dilihat bahwa angka-angka setiap sel pada tabel tersebut memiliki makna ganda. Angka dari suatu sel pada transaksi antara, misalnya $x_{12}$, jika dilihat menurut baris maka angka tersebut menunjukkan besarnya output sektor 1 yang dialokasikan untuk memenuhi permintaan antara di sektor 2. Sedangkan jika dilihat menurut kolom, maka $x_{12}$ menunjukkan besarnya input yang digunakan oleh sektor 2 yang berasal dari sektor 1 .

Dari gambaran tersebut tampak bahwa penyusunan angka-angka dalam bentuk matriks memperlihatkan suatu jalinan yang saling mengait dari berbagai kegiatan antar sektor. Sebagai ilustrasi dapat diamati proses pengalokasian output pada Tabel 2 .

Output sektor 1 pada tabel tersebut adalah sebesar $X_{1}$ dan didistribusikan 


\section{Tabel 2. Ilustrasi Tabel Input-Output untuk Sistem Perekonomian dengan $\boldsymbol{n}$ Sektor Produksi}

Table 2. IIlustration of Input -Output Table for the Economic System with n-Production Sector

\begin{tabular}{|c|c|c|c|c|c|c|c|c|}
\hline \multirow{2}{*}{$\begin{array}{l}\text { Struktur Input } \\
\text { (Input Structure }\end{array}$} & \multirow{2}{*}{\multicolumn{2}{|c|}{$\begin{array}{l}\text { Alokasi Output } \\
\text { (Output Allocation) }\end{array}$}} & \multicolumn{4}{|c|}{$\begin{array}{c}\begin{array}{c}\text { Permintaan Antara } \\
\text { (Intermediate Demand) }\end{array} \\
\text { Sektor Produksi/ } \\
\text { Production Sector }\end{array}$} & \multirow[t]{2}{*}{$\begin{array}{c}\text { Permintaan } \\
\text { Akhir } \\
\text { (Final } \\
\text { Demand) }\end{array}$} & \multirow[t]{2}{*}{$\begin{array}{c}\text { Total } \\
\text { Output/ } \\
\text { Output... }\end{array}$} \\
\hline & & & 1 & 2 & $\ldots$ & $\mathrm{n}$ & & \\
\hline \multirow{2}{*}{$\begin{array}{c}\text { Input Antara } \\
\text { (Intermediate } \\
\text { Input) }\end{array}$} & \multirow{2}{*}{$\begin{array}{c}\text { Sektor } \\
\text { produksi } \\
\text { (Production } \\
\text { Sector) }\end{array}$} & $\begin{array}{l}1 \\
2\end{array}$ & $\begin{array}{l}x_{11} \\
x_{21}\end{array}$ & $\begin{array}{l}x_{12} \\
x_{22}\end{array}$ & $\cdots$ & $\begin{array}{l}x_{1 \mathrm{n}} \\
x_{2 \mathrm{n}}\end{array}$ & $\begin{array}{l}F_{1} \\
F_{2}\end{array}$ & $\begin{array}{l}\mathrm{X}_{1} \\
\mathrm{X}_{2}\end{array}$ \\
\hline & & $\cdots$ & $x_{n 1}$ & $x_{n 2}$ & $\ldots$ & $x_{n n}$ & $\ddot{F}_{n}$ & $\ddot{X}_{n}$ \\
\hline \multicolumn{3}{|c|}{$\begin{array}{l}\text { Input Primer (Primary Input atau Value } \\
\text { Added) }\end{array}$} & $\mathrm{V}_{1}$ & $V_{2}$ & $\ldots$ & $V_{n}$ & & \\
\hline \multicolumn{3}{|c|}{ Total Input/Input.... } & $\mathrm{X}_{1}$ & $\mathrm{X}_{2}$ & & $x_{n}$ & & \\
\hline
\end{tabular}

sepanjang baris sebesar $x_{11}, x_{12}$, hingga $x_{1 n}$ masing-masing untuk memenuhi permintaan antara sektor 1,2 hingga sektor $n$.

Sedangkan sisanya sebesar $F_{1}$ digunakan untuk memenuhi permintaan akhir. Begitu juga dengan output sektor 2 hingga $n$ masing-masing sebesar $X_{2}$ hingga $X n$, dapat dilihat dengan cara yang sama dalam proses pengalokasian output sektor 1. Alokasi output pada masing-masing sektor tersebut dalam bentuk persamaan aljabar dapat dituliskan sebagai berikut:

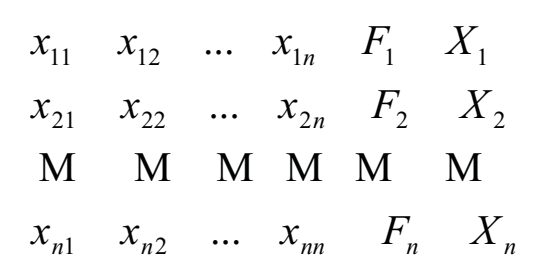

Dan secara ringkas persamaan di atas dapat dirumuskan kembali menjadi:

$$
\sum_{j=1}^{n} x_{i j}+F_{i}=X_{i} \quad \text { untuk } j=1,2, \ldots, n
$$

dimana:

$x_{i j}=$ Output sektor i yang digunakan sebagai input sektor j/Output of sector i used as input to sector $j$
$F_{\mathrm{i}}=$ Permintaan akhir terhadap sektor I/ Final demand of sector $i$ /

$X_{i}=$ Jumlah output sektor ITotal sector output

Apabila angka-angka dibaca menurut kolom, khususnya pada transaksi antara, maka angka pada kolom (sektor) tertentu menunjukkan berbagai input yang diperlukan dalam proses produksi pada sektor tersebut. Apabila Tabel 1 digunakan sebagai ilustrasi, maka persamaan aljabar untuk input yang digunakan oleh masing-masing sektor dapat dituliskan sebagai berikut:

$$
\left[\begin{array}{c}
x_{11}+x_{21}+\ldots+x_{n 1}+F_{1}=X_{1} \\
x_{12}+x_{22}+\ldots+x_{n 2}+F_{2}=X_{2} \\
\mathrm{M} \mathrm{M} \mathrm{M} \mathrm{M} \mathrm{M} \mathrm{M} \\
x_{1 n}+x_{2 n}+\ldots+x_{n n}+F_{n}=X_{n}
\end{array}\right]
$$

dimana :

$x_{i j}=$ Input sektor $\mathrm{i}$ yang digunakan sebagai output sektor j/Input sector $i$ used as an output sector $j$

$F_{\mathrm{i}}=$ Permintaan akhir terhadap sektor i/ Final demand of sector $i$

$X_{i}=$ Jumlah input sektor $i$ I Total of input sector $i$ dan secara ringkas dapat ditulis menjadi:

$\sum_{j=1}^{n} X_{i j}+F_{i}=X_{i} \quad$ untuk $j=1,2, \ldots, n$ 
dimana :

$V_{j}=$ Nilai tambah atau input primer sektor j/Value-added or primary input sector $j$

$X j=$ Jumlah input sektor $\mathrm{j} /$ Total of input sector $i$

Persamaan-persamaan tersebut merupakan persamaan dasar yang sangat penting, khususnya untuk melakukan analisis perekonomian dengan pendekatan model Input-Output.

\section{Jenis dan Sumber Data}

Jenis data yang digunakan dalam kajian ini merupakan data sekunder yang diperoleh dari buku Tabel Input-Output Tahun 2005 yang disusun oleh Badan Pusat Statistik Provinsi Sulawesi Utara (2006) menurut klasifikasi matrik 48 × 48 sektor. Tabel I-O tersebut merupakan tabel transaksi domestik atas dasar harga produsen, dimana setiap nilai transaksi hanya mencakup barang dan jasa domestik dan dinilai atas dasar harga produsen dalam satuan juta rupiah. Penyusunan Tabel I-O ini dimaksudkan untuk menyajikan gambaran tentang hubungan timbal balik dan saling keterkaitan antar satuan kegiatan (sektor) dalam perekonomian di Sulawesi Utara secara menyeluruh. Dalam kajian ini, Tabel I-O tersebut diklasifikasikan kembali sesuai dengan kepentingan analisis dengan cara melakukan agregasi beberapa sektor sehingga menjadi klasifikasi matriks 11 x 11 sektor, seperti yang terdapat pada Tabel 3.

\section{Metoda Analisis Data}

Metode analisis data yang digunakan dalam kajian ini adalah analisis keterkaitan. Konsep keterkaitan biasa digunakan sebagai

Tabel 3. Pengklasifikasian Sektor-Sektor dari Tabel Input-Output di Provinsi Sulawesi Utara Tahun 2005 (Matriks Ukuran 11 x 11 Sektor)

Table 3. Sectors Re-classification from Input-Output Table in North Sulawesi Province years 2005 (Matrix Size $11 \times 11$ Sectors)

\begin{tabular}{|c|c|c|}
\hline $\begin{array}{l}\text { Sektorl } \\
\text { Sector }\end{array}$ & $\begin{array}{l}\text { Deskripsi/ } \\
\text { Description }\end{array}$ & $\begin{array}{l}\text { Sektor-Sektor dalam Tabel } \\
\text { Input-Output/ } \\
\text { Sectors in Input Output Table }\end{array}$ \\
\hline & \multirow{3}{*}{$\begin{array}{l}\text { Perikanan Primer/Primary Fisheries:: } \\
\text { - Perikanan laut dan hasil perairan laut } \\
\text { lainnya/ Marine fisheries and its produces } \\
\text { - Perikanan darat dan hasil perairan darat }\end{array}$} & \\
\hline 1. & & 14 \\
\hline 2. & & 15 \\
\hline & \multirow{2}{*}{$\begin{array}{l}\text { Perikanan Sekunder/Secondary Fisheries : } \\
\text { - Industri pengolahan hasil non perikanan/Non } \\
\text { fisheries processing industries }\end{array}$} & 15 \\
\hline 3. & & \\
\hline 4. & - Industri pengeringan dan penggaraman & \\
\hline 5. & \multirow{2}{*}{$\begin{array}{l}\text { ikan/Drying and salting fisheries industries } \\
\text { - Industri pengolahan dan pengawetan } \\
\text { ikan/Processing and preserving fisheries industries }\end{array}$} & $18-21$ \\
\hline & & \\
\hline 6. & \multirow{2}{*}{$\begin{array}{l}\text { Pariwisata Bahari/Maritime tourism } \\
\text { Pertanian non perikanan/ Non fisheries agriculture }\end{array}$} & $31-48$ \\
\hline 7. & & $1-13$ \\
\hline 8. & \multirow{2}{*}{$\begin{array}{l}\text { Pertambangan dan Penggalian/ Mining and quarry } \\
\text { Industri non makanan/ Non food industry }\end{array}$} & $16-17$ \\
\hline 9. & & $22-29$ \\
\hline 10. & $\begin{array}{l}\text { Industri non makanan lainnya/ } \\
\text { Others non food industry }\end{array}$ & 30 \\
\hline 11. & $\begin{array}{l}\text { Jasa dan lainnya non pariwisata bahari/ } \\
\text { Service and others non maritime tourism }\end{array}$ & $31-48$ \\
\hline
\end{tabular}

Sumber: Modifikasi Tabel I-O 48 Sektor ke dalam Tabel I-O 11 Sektor dari BPS Sulawesi Utara (2006)

Source: Modification of Input Output Table 48 Sector in Input Output Table 11 Sector from BPS North Sulawesi (2006) 
dasar perumusan strategi pembangunan ekonomi dengan melihat keterkaitan antar sektor dalam suatu sistem perekonomian. Konsep keterkaitan biasa dirumuskan meliputi (I) keterkaitan ke belakang (backward linkage) yang menunjukkan hubungan keterkaitan antar industri/sektor dalam pembelian barang dan jasa terhadap total pembelian input yang digunakan untuk proses produksi dan (ii) keterkaitan ke depan (forward linkage) yang menunjukkan hubungan keterkaitan antar industri/sektor dalam penjualan barang dan jasa terhadap total penjualan output yang dihasilkannya. Berdasarkan konsep ini dapat diketahui besarnya pertumbuhan suatu sektor yang dapat menstimulasi pertumbuhan sektor lainnya melalui mekanisme induksi. Keterkaitan langsung antar sektor perekonomian dalam pembelian dan penjualan input antara ditunjukkan oleh koefisien langsung, sedangkan keterkaitan langsung dan tidak langsungnya dtunjukkan dari matriks kebalikan Leontief (Priyarsono, et al., 2007). Secara rinci uraian jenis-jenis keterkaitan tersebut adalah sebagai berikut.

\section{A. Keterkaitan Langsung dan Tidak Langsung ke Depan dan ke Belakang}

\section{- Keterkaitan langsung ke belakang}

Keterkaitan langsung ke belakang menunjukkan akibat dari suatu sektor tertentu terhadap sektor-sektor yang menyediakan input antara bagi sektor tersebut secara langsung per unit kenaikan permintaan total. Secara matematis keterkaitan langsung ke belakang tersebut diformulasikan sebagai berikut:

$$
K L B i=a_{1 j}+a_{2 j}+\ldots+a_{n j}=\sum_{i=1}^{n} a_{i j}
$$

dimana:

$$
\begin{aligned}
K L B i= & \text { Keterkaitan langsung ke belakang / } \\
& \text { Backward directlinkage } \\
a_{i j}= & \text { Unsur matriks koefisien teknis, yang } \\
& \text { diperoleh dari rasio I-O permintaan } \\
& \text { jumlah input antara dari sektor ke-i }
\end{aligned}
$$

untuk sektor ke-j (xij) terhadap total input sektor ke-j (Xj)/ Coefficient matrix as result from demand of intermediate input of sector i for sector j total of input sector $j$

\section{- Keterkaitan tidak langsung ke belakang}

Secara umum keterkaitan langsung dan tidak langsung ke belakang menyatakan akibat dari suatu sektor yang diteliti terhadap sektor-sektor yang menyediakan input antara bagi sektor tersebut baik secara langsung maupun tidak langsung per unit kenaikan permintaan total, sehingga secara matematis diformulasikan sebagai berikut:

$$
K T L B i=b_{1 j}+b_{2 j}+\ldots+b_{n j}=\sum_{i=1}^{n} b_{i j}
$$

dimana:

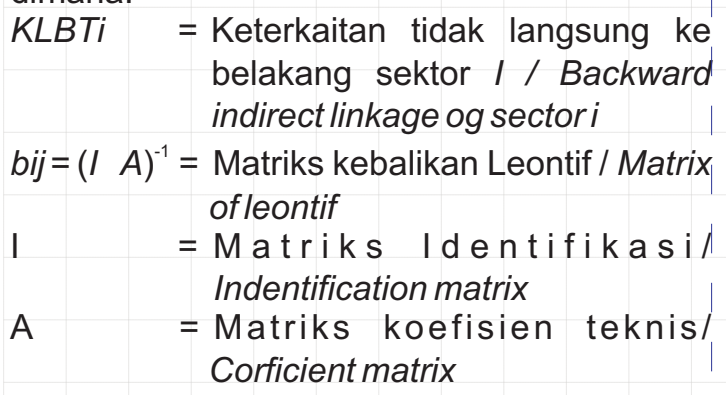

\section{- Keterkaitan langsung ke depan}

Keterkaitan langsung ke depan menunjukkan akibat suatu sektor tertentu terhadap sektor-sektor yang menggunakan sebagain output sektor tersebut secara langsung per unit kenaikan permintaan total. Secara matematis keterkaitan langsung ke depan diformluasikan sebagai berikut:

$$
K L D i=a_{1 j}+a_{2 j}+\ldots+a_{n j}=\sum_{j=1}^{n} a_{i j}
$$

$K L D i=$ Keterkaitan langsung ke depan/ Forward direct linkage

$a_{i j} \quad=$ unsur matriks koefisien teknis, yang diperoleh dari rasio I-O permintaan jumlah input antara dari sektor ke-i untuk sektor ke-j (xij) terhadap total input sektor ke-j $(X j) / C o e f f i c i e n t$ 
matrix as a result from demand of intermediate input of sector I for sector j to total of input sectorj

\section{- Keterkaitan tidak langsung ke depan}

Keterkaitan langsung dan tidak langsung ke depan menunjukkan akibat dari suatu sektor tertentu terhadap sektor-sektor yang menggunakan output bagi sektor tersebut secara langsung maupun tidak langsung per unit kenaikan permintaan total, sehingga secara matematis diformulasikan sebagai berikut:

$$
K T L D i=\sum_{j=i}^{n} b i j
$$

dimana:

$$
\begin{aligned}
\text { KTLDi }= & \text { Keterkaitan tidak langsung ke depan } \\
& \text { sektor I/Backward indirect linkage of } \\
& \text { sector } i \\
b_{i j}= & \text { Matriks kebalikan Leontif /Matrix of } \\
& \text { Leontif }
\end{aligned}
$$

\section{B. Keterkaitan total ke belakang dan ke depan}

Derajat keterkaitan total diperoleh dari hasil penjumlahan dari derajat keterkaitan langsung dan tidak langsung (baik untuk keterkaitan ke belakang maupun ke depan). Selanjutnya untuk keperluan perbandingan keterkaitan sektor yang diamati dengan ratarata keseluruhan sektor dalam perekonomian Sulawesi Utara, dilakukan perhitungan indeks keterkaitan ke belakang (daya penyebaran) dan indeks keterkaitan ke depan (daya kepekaan). Secara rinci uraian kedua jenis kedua jenis indeks tersebut adalah sebagai berikut (Kuncoro, 2006 dalam Tajerin et al., 2007).

\section{- Indeks keterkaitan total ke belakang (daya penyebaran total)}

Indeks daya penyebaran memberikan gambaran tentang kemampuan suatu sektor untuk meningkatkan pertumbuhan industri hulunya atau juga digunakan untuk mengetahui distribusi manfaat dari pengembangan suatu sektor terhadap perkembangan sektor-sektor lainnya melalui mekanisme transaksi pasar input. Sehingga secara matematis dapat diformulasikan sebagai berikut:

$$
I D P_{j}=\frac{\sum_{i} T B L_{i j}}{\left(\frac{1}{n}\right) \sum_{i} \sum_{j} T B L_{i j}}
$$

$I D P_{j} \quad=$ Indeks daya penyebaran sektor ke-j/ Index of dispersion of sector $-i$

$T B L_{i j}=$ Total keterkaitan ke belakang (penjumlahan dari keterkaitan langsung ke belakang dan keterkaitan tidak langsung ke belakang) dari sektor $i$ ke sektor $j /$ Total of backward linkage sector of indirect linkage of sector I to sector $j j$

$n=$ Jumlah sektor dalam tabel input output yang dianalisis/ Total sector in input -output tabel

\section{- Indeks keterkaitan total ke depan (derajat kepekaan total)}

Indeks keterkaitan ke depan (derajat kepekaan) digunakan untuk mengetahui tingkat kepekaan suatu sektor terhadap sektor-sektor lainnya melalui mekanisme pasar output, atau dapat juga diartikan sebagai kemampuan suatu sektor untuk mendorong pertumbuhan produksi sektor-sektor lain yang memakai input dari sektor ini. Sehingga secara matematis dapat diformulasikan sebagai berikut:

$I D K_{i}=\frac{\sum_{j} T F L_{i j}}{\left(\frac{1}{n}\right) \sum_{i} \sum_{j} T F L_{i j}}$

dimana:

$I D P_{i}=$ Indeks derajat kepekaan sektor ke-i/ Index of sensitivity of sector $-i$

$T F L_{i j} \quad$ =total keterkaitan ke depan (penjumlahan dari keterkaitan langsung ke depan dan keterkaitan tidak langsung ke depan) dari sektor $i$ ke sektor $j /$ Total of direct and indirect forward of sector i to sector $j$ 
$n \quad=$ Jumlah sektor dalam tabel inputoutput yang dianalisis/ Total sector input - output tabel

\section{HASIL DAN PEMBAHASAN}

\section{A.Keterkaitan Langsung dan Tidak Langsung ke Belakang dan ke Depan}

Keterkaitan langsung dan tidak langsung baik ke depan maupun ke belakang digunakan untuk mengetahui seberapa jauh tingkat hubungan atau keterkaitan antar sektor produksi dalam perekonomian Provinsi Sulawesi Utara Adapun hasil analisisnya seperti diuraikan berikut.

\section{- Keterkaitan langsung dan tidak langsung ke belakang}

Derajat keterkaitan ke belakang (langsung maupun tidak langsung) menunjukkan pengaruh yang ditimbulkan oleh satu unit permintaan akhir terhadap semua sektor dalam perekonomian Sulawesi Utara. Berdasarkan Tabel 4 diketahui bahwa derajat keterkaitan langsung ke belakang untuk semua sektor perekonomian di Sulawesi Utara lebih kecil dibandingkan dengan derajat keterkaitan tidak langsung ke belakang. Artinya bahwa secara langsung semua sektor perekonomian yang ada di Sulawesi Utara belum menunjukkan hubungan yang kuat. Pada Tabel 4 terlihat bahwa derajat total ratarata sektor perikanan $(2,011)$ lebih besar dibandingkan dengan derajat total rata-rata seluruh sektor perekonomian di Sulawesi Utara $(1,973)$. Untuk sektor perikanan primer (perikanan laut maupun darat), derajat keterkaitan belakang (secara langsung maupun tidak langsung) lebih kecil jika dibandingkan dengan derajat rata-rata sektor perikanan. Secara langsung derajat keterkaitan sektor perikanan primer (laut dan darat) masing-masing sebesar 0,219 dan 0,199 . Hal ini berarti bahwa untuk masingmasing sektor perikanan (laut maupun darat) dalam aktivitasnya menggunakan input antara masing-masing sebesar $(0,219$ dan 0,199$)$ satuan untuk setiap satu-satuan peningkatan permintaan akhir sektor perikanan (laut maupun darat) tersebut. Sedangkan keterkaitan tidak langsung ke belakang untuk seluruh sektor yang ada di Sulawesi Utara menunjukkan derajat keterkaitan yang lebih dari satu, yang berarti bahwa seluruh sektor tersebut menunjukkan hubungan/keterkaitan yang kuat dalam mendukung perekonomian Sulawesi Utara. Dari Tabel 4 terlihat bahwa untuk sektor perikanan (laut maupun darat) derajat keterkaitan ke belakangnya sebesar 1,176 dan 1,035, hal ini berarti bahwa bila permintaan akhir masing-masing sektor perikanan meningkat satu unit, output seluruh sektor perekonomian di Sulawesi Utara akan meningkat masing-masing sebesar $(1,176$ dan 1,035$)$ unit.

Untuk perikanan sekunder terdiri dari industri pengolahan hasil non perikanan, industri pengeringan dan penggaraman ikan dan industri pengolahan dan pengawetan ikan. Dari ketiga industri tersebut, secara tidak langsung industri pengolahan hasil non perikanan mempunyai derajat keterkaitan ke belakang yang lebih besar dari rata-rata sektor perikanan dan rata-rata seluruh sektor yaitu 1,841 , sedangkan untuk industri pengeringan dan penggaraman ikan serta industri pengolahan dan pengawetan ikan masingmasing sebesar 1,000 dan 1,027. Meskipun derajat keterkaitan secara langsung industri pengolahan dan pengawetan ikan berada dibawah rata-rata sektor perikanan, akan tetapi secara keseluruhan, sektor perikanan sekunder mempunyai derajat keterkaitan ke belakang (secara tidak langsung) yang lebih besar dari satu, walaupun secara peringkat hanya menduduki peringkat kedua, ketujuh dan keenam.

Untuk sektor pariwisata bahari, secara langsung memiliki derajat keterkaitan ke belakang yang lebih besar dari rata-rata sektor perikanan yaitu sebesar 0,798. Jika dilihat dari derajat keterkaitan ke belakang secara total, pariwisata bahari memiliki nilai yang lebih besar dari rata-rata sektor perikanan dan seluruh sektor dalam perekonomian Sulawesi Utara. 
Tabel 4. Derajat dan Peringkat Keterkaitan Langsung dan Tidak Langsung ke Belakang Sektor-Sektor dalam Perekonomian Sulawesi Utara Tahun 2005

Table 4. Degree and Level of Direct and Indirect Backward Linkage of Sectors in the Economy of North Sulawesi Years 2005

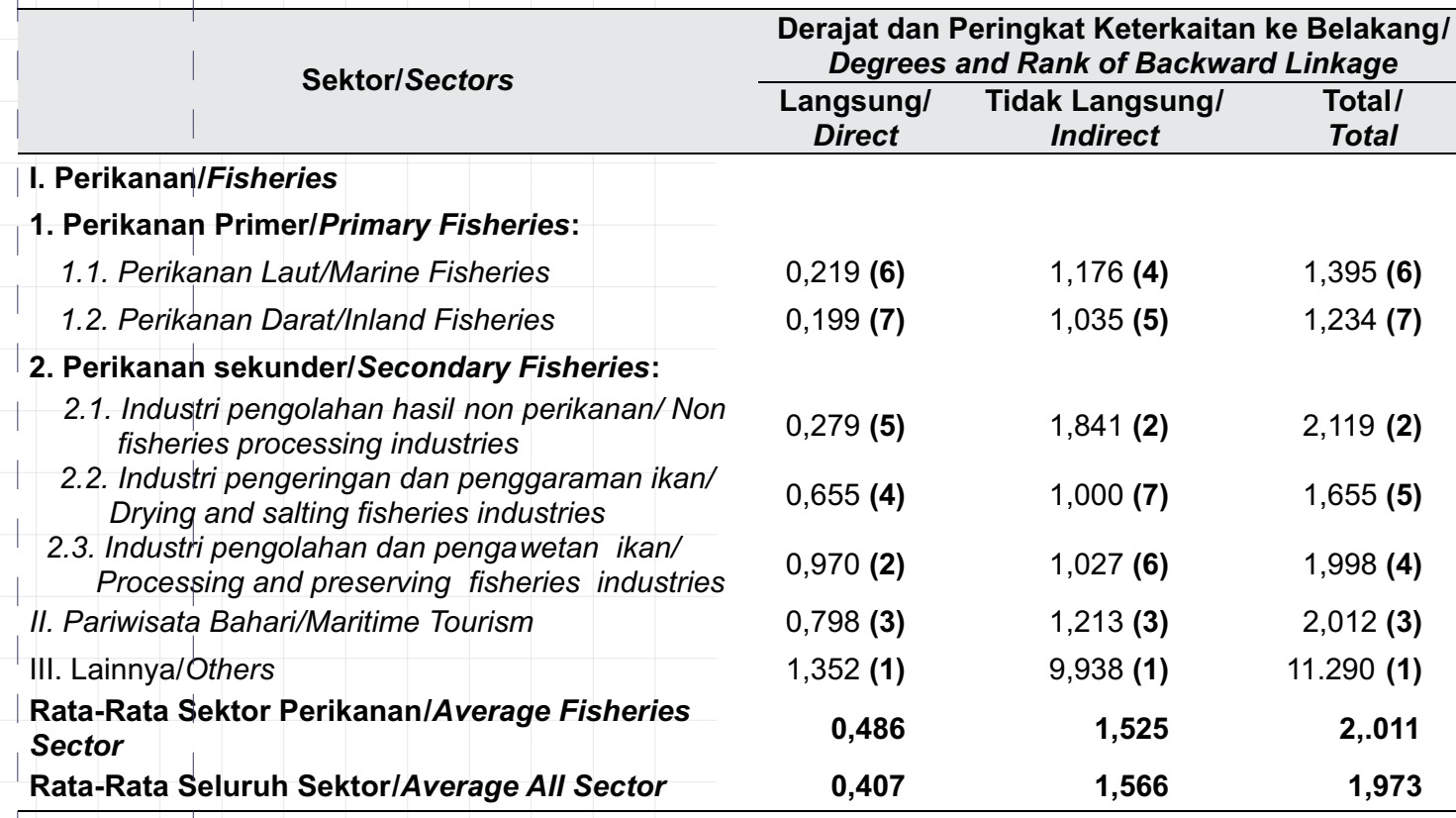

Sumber: Hasil Pengolahan Data Tabel Input Output Provinsi Sulawesi Utara, 2005

Source: Result of Data Processing Input Output Table North Sulawesi Province, 2005

Keterangan: Angka dalam kurung (...) menunjukkan peringkat derajat keterkaitan ke belakang

Remarks: (...) is rank of backward linkage

Berdasarkan Tabel 4 diketahui bahwa derajat keterkaitan ke belakang secara total didominasi oleh sektor lainnya yang merupakan gabungan dari industri non makanan, industri non makanan lainnya, jasa dan lainnya non pariwisata bahari, pertanian non perikanan dan pertambangan dan penggalian yang menduduki peringkat ke satu, kemudian perikanan sekunder (sektor industri pengolahan hasil non perikanan) yang menduduki peringkat kedua dan pariwisata yang menduduki peringkat ketiga. Dari gambaran tersebut terlihat bahwa peranan sektor perikanan dalam perekonomian di Sulawesi Utara cukup besar, terutama dalam bidang industri dan pariwisata.

\section{- Keterkaitan langsung dan tidak langsung ke depan}

Keterkaitan langsung ke depan menunjukkan berapa banyak output suatu sektor yang digunakan oleh sektor-sektor lain sebagai input, sedangkan keterkaitan tidak langsung ke depan menunjukkan seberapa besar suatu sektor memenuhi permintaan akhir dari seluruh sektor perekonomian. Berdasarkan Tabel 5 terlihat bahwa secara langsung derajat keterkaitan ke depan terjadi indikasi penguatan pada sektor lainnya yang menduduki peringkat pertama, kemudian perikanan sekunder industri pengolahan hasil non perikanan) yang menduduki peringkat kedua, dan perikanan primer (perikanan laut) 
yang menduduki peringkat ketiga. Sedangkan secara tidak langsung derajat keterkaitan ke depan yang menduduki peringkat ke-2 adalah sektor industri pengolahan dan pengawetan ikan (perikanan sekunder) dan pariwisata bahari yang menduduki peringkat ketiga. Dari tabel terlihat bahwa sektor industri pengolahan $(2,282)$ dan industri pariwisata bahari $(2,146)$ mempunyai derajat keterkaitan ke depan yang lebih besar dari rata-rata sektor perikanan dan rata-rata seluruh sektor. Hal ini berarti secara tidak langsung sektor tersebut mempunyai keterkaitan/hubungan yang kuat dalam perekonomian Sulawesi Utara dengan nilai yang lebih besar dari satu.

Sedangkan untuk kelompok perikanan primer (perikanan laut dan darat) secara tidak langsung, derajat keterkaitan kedepan untuk masing-masing sektor menunjukkan hubungan atau keterkaitan yang kuat dalam perekonomian Sulawesi Utara, karena nilai masing-masing sektor lebih besar dari satu (1). Untuk sektor perikanan (laut maupun darat) masing-masing sebesar 1,312 dan 1,283 , hal ini berarti setiap peningkatan permintaan akhir seluruh sektor perekonomian di Sulawesi Utara sebesar satu unit, sektor perikanan mampu memenuhinya masing-masing sebesar (1,312 dan 1,283) unit.

Dari Tabel 5 terlihat bahwa derajat keterkaitan ke belakang secara total didominasi oleh sektor lainnya yang menduduki peringkat pertama, kemudian

Tabel 5. Derajat dan Peringkat Keterkaitan Langsung dan Tidak Langsung ke Depan Sektor-Sektor dalam Perekonomian Sulawesi Utara Tahun 2005

Table 5. Degree and Level of Direct and Indirect Forward Linkage of Sectors in the Economy of North Sulawesi Years 2005

\begin{tabular}{|c|c|c|c|}
\hline \multirow{2}{*}{ Sektor/Sector } & \multicolumn{3}{|c|}{$\begin{array}{c}\text { Derajat dan Peringkat Keterkaitan ke } \\
\text { Depan/Degrees and Rank of Forward } \\
\text { Linkage }\end{array}$} \\
\hline & $\begin{array}{l}\text { Langsung/ } \\
\text { Direct }\end{array}$ & $\begin{array}{l}\text { Tidak } \\
\text { Langsung/ } \\
\text { Indirect }\end{array}$ & $\begin{array}{l}\text { Total } / \\
\text { Total }\end{array}$ \\
\hline I. Perikanan/Fisheries & & & \\
\hline 1. Perikanan Primer/Primary Fisheries: & & & \\
\hline 1.1. Perikanan Laut/Marine Fisheries & \multirow{2}{*}{$\begin{array}{l}0,163(3) \\
0,034(5)\end{array}$} & $1,312(6)$ & $1,475(6)$ \\
\hline 1.2. Perikanan Darat/Inland Fisheries & & $1,283(7)$ & $1,317(7)$ \\
\hline 2. Perikanan sekunder/Secondary Fisheries: & & & \\
\hline $\begin{array}{l}\text { 2.1. Industri pengolahan hasil non perikanan/ } \\
\text { Non fisheries processing industries } \\
\text { 2.2. Industri pengeringan dan penggaraman ikan/ }\end{array}$ & $0,548(2)$ & $1,385(5)$ & $1,933(4)$ \\
\hline $\begin{array}{l}\text { Drying and salting fisheries industries } \\
\text { 2.3. Industri pengolahan dan pengawetan ikan/ }\end{array}$ & $0,000(7)$ & $1,874(4)$ & $1,874(5)$ \\
\hline Processing and preserving fisheries industries & $0,024(6)$ & $2,282(2)$ & $2,306(2)$ \\
\hline II. Pariwisata Bahari/Maritime Tourism & \multirow{2}{*}{$\begin{array}{l}0,136(4) \\
3,568(1)\end{array}$} & \multirow{2}{*}{$\begin{array}{l}2,146(3) \\
6,949(1)\end{array}$} & $2,282(3)$ \\
\hline III. Lainnya/Others & & & $10,517(1)$ \\
\hline $\begin{array}{l}\text { Rata-Rata Sektor Perikanan/Average Fisheries } \\
\text { Sector }\end{array}$ & $0, .346$ & $1, .669$ & 2,015 \\
\hline Rata-Rata Seluruh Sektor/Average All Sector & 0,407 & 1,566 & 1,973 \\
\hline
\end{tabular}

Sumber : Hasil Pengolahan Data Tabel Input Output Provinsi Sulawesi Utara, 2005

Source: Result of Data Processing Input Output Table North Sulawesi Province, 2005

Keterangan : Angka dalam kurung (...) menunjukkan peringkat derajat keterkaitan ke depan

Remarks: (...) is rank of forward linkage 
Tabel 6. Indeks Keterkaitan Total ke Belakang Sektor-Sektor dalam Perekonomian Sulawesi Utara Tahun 2005

Table 6. Index of Total Backward of Linkage Sectors in the Economy North Sulawesi, 2005

\section{Sektor/Sectors}

\section{Indeks Keterkaitan Total Ke}

Belakang/Index of Total

Backward Linkage
Kategori/

Category

\section{Perikanan/Fisheries}

\section{Perikanan Primer/Primary Fisheries:}
1.1. Perikanan Laut/Marine Fisheries
0,707
rendah/low
1.2. Perikanan Darat/Inland Fisheries
0,626
rendah/low

2. Perikanan sekunder/Secondary Fisheries:
2.1. Industri pengolahan hasil non perikanan/
Non fisheries processing industries
1,074
tinggi/high
2.2. Industri pengeringan dan penggaraman
ikan/ Drying and salting fisheries industries
0,839
rendah/low
2.3. Industri pengolahan dan pengawetan ikan/
Processing and preserving fisheries industries
1,013
tinggi/high
II. Pariwisata Bahari/Marrine Tourism
1,020
tinggi/high
III. Lainnya/Others
5,722
tinggi/high

Sumber: Hasil Pengolahan Data Tabel Input Output Provinsi Sulawesi Utara, 2005

Source: Result of Data Processing Input Output Table North Sulawesi Utara Province, 2005

perikanan sekunder (sektor industri pengolahan dan pengawetan ikan) yang menduduki peringkat kedua dan pariwisata bahari yang menduduki peringkat ketiga. Dari gambaran tersebut terlihat bahwa peranan sektor perikanan dalam perekonomian di Sulawesi Utara cukup besar, terutama dalam bidang industri pengolahan dan pengawetan ikan yang ditunjukkan dengan derajat total keterkaitan ke depan sebesar 2,306 .

\section{B. Keterkaitan Total ke Belakang dan ke Depan}

\section{- Indeks keterkaitan total ke belakang (daya penyebaran total)}

Indeks keterkaitan total ke belakang memberikan gambaran tentang kemampuan suatu sektor untuk meningkatkan pertumbuhan industri hulunya atau juga digunakan untuk mengetahui distribusi manfaat dari pengembangan suatu sektor terhadap perkembangan sektor-sektor lainnya melalui mekanisme transaksi pasar input.

Berdasarkan Tabel 6 terlihat bahwa untuk sektor perikanan primer (laut maupun darat) memiliki indeks keterkaitan total ke belakang yang lebih kecil dari satu yaitu masing-masing sebesar 0,707 dan 0,626. Hal ini berarti bahwa untuk setiap peningkatan satu unit output sektor perikanan (laut maupun darat) akan menyebabkan naiknya output sektorsektor lain (termasuk sektor perikanan itu sendiri baik laut maupun darat) secara keseluruhan masing-masing sebesar $(0,707$ dan 0,626) unit. Berdasarkan indeks keterkaitan total ke belakang, sektor perikanan (laut maupun darat) masuk ke dalam kategori yang rendah. Sedangkan sektor perikanan sekunder (industri pengolahan hasil non perikanan dan industri pengolahan dan pengawetan ikan) memiliki nilai masing-masing sebesar 1,074 dan 1,013 dan termasuk dalam kategori tinggi. Untuk 
sektor pariwisata bahari termasuk dalam kategori tinggi dengan nilai sebesar 1,020. Hal ini mengindikasikan bahwa indeks penyebaran sektor perikanan dan pariwisata bahari dalam perekonomian Sulawesi Utara menunjukkan indeks penyebaran yang tinggi terhadap sektor-sektor lain yang ada dalam perekonomian Sulawesi Utara.

\section{- Indeks keterkaitan total ke depan (derajat kepekaan total)}

Indeks keterkaitan total ke depan untuk mengetahui tingkat kepekaan suatu sektor terhadap sektor-sektor lainnya melalui mekanisme pasar output, seperti yang terlihat pada Tabel 7.

Berdasarkan Tabel 7 diketahui bahwa indeks keterkaitan total ke depan sektor perikanan (laut maupun darat) termasuk dalam kategori rendah, sedangkan untuk perikanan sekunder (khususnya untuk sektor industri pengolahan dan pengawetan ikan) serta pariwisata bahari termasuk dalam kategori tinggi dengan nilai masing-masing sebesar 1,169 dan 1,157, hal ini berarti bahwa setiap kenaikan satu unit output sektor industri pengolahan dan pengawetan ikan serta pariwisata bahari membutuhkan output sektor lainnya sebagai input masing-masing sebesar $(1,169$ dan 1,157) unit. Dari Tabel 7 terlihat bahwa sektor perikanan mempunyai daya dorong dan daya tarik yang lebih besar khususnya untuk kelompok perikanan sekunder (industri pengolahan dan pengawetan ikan) dan sektor pariwisata bahari yang memiliki peran dalam pembangunan perekonomian di Sulawesi Utara.

Berdasarkan indeks keterkaitan ke belakang dan ke depan, pengelompokkan sektor-sektor ekonomi di Provinsi Sulawesi Utara dapat digolongkan ke dalam empat (4) kelompok yaitu sektor potensial, unggulan/andalan, kurang berkembang dan jenuh. Adapun yang termasuk dalam kelompok sektor andalan/unggulan adalah industri pengolahan dan pengawetan ikan (perikanan sekunder), pariwisata bahari dan lainnya. Sektor kurang berkembang terdiri dari perikanan laut dan perikanan darat (perikanan primer), serta industri pengeringan

\section{Tabel 7. Indeks Keterkaitan Total ke Depan Sektor-Sektor dalam Perekonomian Sulawesi Utara Tahun 2005}

Table 7. Index of Total Forward Linkage of Sectors in the Economy of North Sulawesi ,2005

$\begin{array}{ccc}\text { Sektor/Sectors } & \begin{array}{c}\text { Indeks Keterkaitan Total } \\ \text { Ke Depan/Index of Total } \\ \text { Forward Linkage }\end{array} & \begin{array}{c}\text { Kategori/ } \\ \text { Category }\end{array} \\ & \end{array}$

\section{Perikanan/Fisheries}

\section{Perikanan Primer/Primary Fisheries:}
1.1. Perikanan Laut/Marine Fisheries
Rendah/low
1.2. Perikanan Darat/Inland Fisheries
0,667
Rendah/low

\section{Perikanan Sekunder/Secondary Fisheries:}

2.1. Industri pengolahan hasil non perikanan/ Non fisheries processing industries

Rendah/low

2.2. Industri pengeringan dan penggaraman ikan/Drying and salting fisheries industries

0,950 Rendah/low

2.3. Industri pengolahan dan pengawetan ikan Processing and preserving fisheries industries

\begin{tabular}{|l|l|}
\hline 1,169 & Tinggi/high \\
1,157 & Tinggi/high \\
5,330 & Tinggi/high \\
\hline
\end{tabular}

II. Pariwisata Bahari/Marrine Tourism 
dan penggaraman ikan (perikanan sekunder) Sedangkan kelompok sektor jenuh adalah industri pengolahan hasil non perikanan. Dari uraian di atas dapat dilihat bahwa sektor industri pengolahan dan pengawetan ikan dan pariwisata bahari dalam peta keterkaitan ekonomi di Sulawesi Utara termasuk sektor andalan/unggulan, artinya sektor tersebut mempunyai indeks keterkaitan ke belakang dan ke depan yang lebih dari rata-rata semua sektor, sehingga sektor tersebut mempunyai peranan yang sangat menentukan terhadap perekonomian di Provinsi Sulawesi Utara, seperti yang terlihat pada Gambar 1 . keterkaitan yang lebih besar dari satu. Indikasi penguatan keterkaitan ke belakang terjadi terutama pada sektor perikanan sekunder, yaitu pada sub sektor industri pengolahan hasil non perikanan dan industri pengolahan dan pengawetan ikan serta pada sektor pariwisata bahari. Sedangkan indeks penguatan keterkaitan ke depan terjadi pada sektor industri pengolahan dan pengawetan ikan dan sektor pariwisata bahari.

Selain itu, pengelompokkan sektor ekonomi di Provinsi Sulawesi Utara berdasarkan indeks keterkaitan ke belakang dan ke depan menunjukkan bahwa sektor

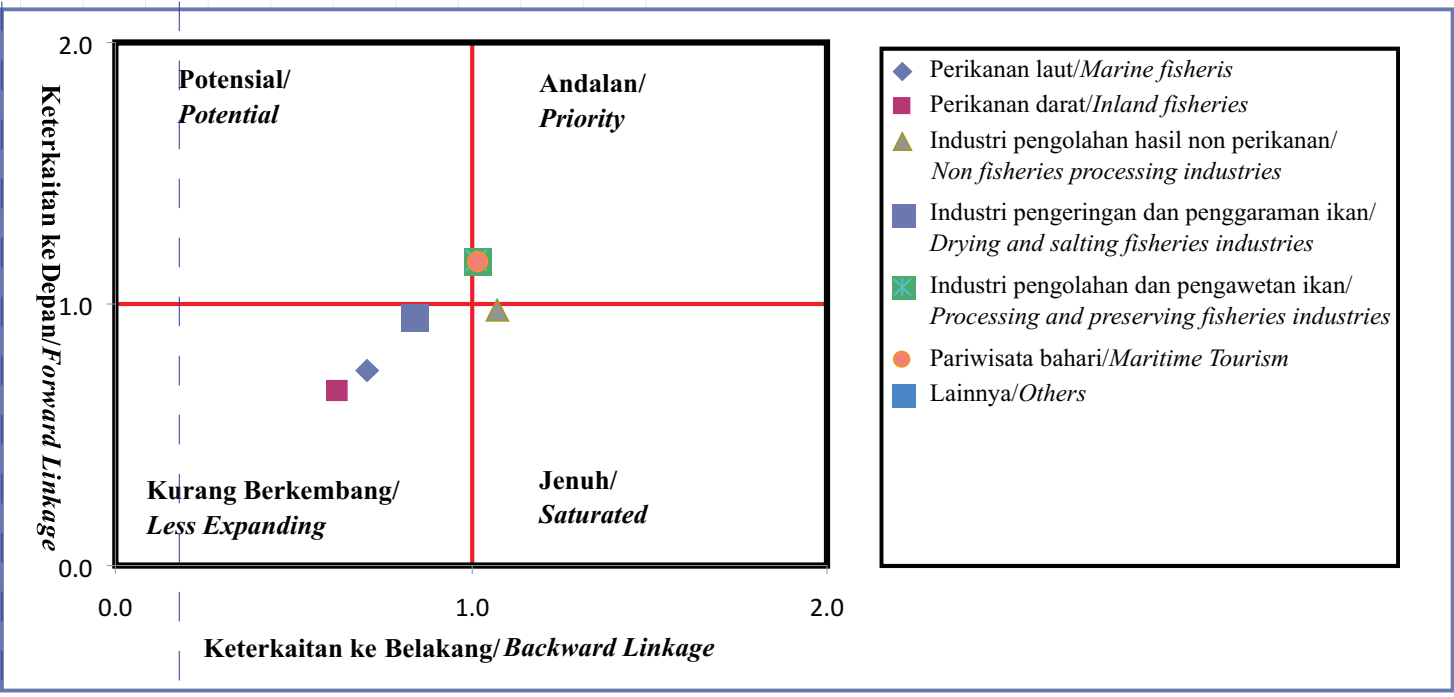

\section{Gambar 1. Pengelompokkan Sektor Ekonomi di Provinsi Sulawesi Utara Berdasarkan Daya Penyebaran Total dan Derajat Kepekaan Total}

Figure 1. Grouping of Economic Sector in the Province of North Sulawesi Based on Total Dispersion Model and Total Degree of Sensitivity

\section{KESIMPULAN DAN IMPLIKASI KEBIJAKAN}

\section{Kesimpulan}

Secara rata-rata keterkaitan sektor perikanan (keterkaitan total ke belakang dan ke depan) dalam perekonomian di Sulawesi Utara tergolong kuat, karena semua sektor perikanan baik primer, sekunder maupun pariwisata bahari mempunyai derajat industri pengolahan dan pengawetan ikan dan pariwisata bahari termasuk sektor andalan/unggulan, artinya sektor tersebut mempunyai peranan yang sangat menentukan dalam peta keterkaitan perekonomian di Provinsi Sulawesi Utara.

\section{Implikasi Kebijakan}

Berdasarkan hasil kajian ini, rata-rata sektor perikanan baik dari sektor perikanan 
sekunder maupun pariwisata bahari memiliki keterkaitan yang kuat dalam perekonomian Sulawesi Utara (khususnya industri pengolahan dan pengawetan ikan) untuk indeks keterkaitan total ke belakang maupun ke depan, yang ditunjukkan oleh derajat keterkaitan yang lebih dari satu. Sedangkan untuk kelompok perikanan primer (baik laut maupun darat) termasuk dalam kategori rendah. Oleh karena itu, agar sektor perikanan khususnya kelompok perikanan primer mampu menempati peringkat pertama dalam perekonomian Sulawesi Utara untuk tahun yang akan datang, diharapkan adanya peran serta pemerintah untuk menunjang pertumbuhan perekonomian di Sulawesi Utara, dengan cara memberikan kemudahan investasi dan insentif yang lebih nyata lagi terhadap kegiatan sektor perikanan, baik pada perikanan laut maupun darat, antara lain dengan cara mendirikan unit-unit pengolahan dan pelabuhan perikanan yang mendukung kegiatan produksi perikanan, karena mengingat masih terbukanya peluang yang dimiliki oleh Sulawesi Utara, karena sebagian besar wilayah geografisnya adalah laut, sehingga masih banyak sumberdaya yang dapat dimanfaatkan untuk meningkatkan produksi sektor perikanan.

\section{DAFTAR PUSTAKA}

Annonimous. 2007. Tabel Input-Output Indonesia 2005. Jilid I, II dan III. Badan Pusat Statistik. Jakarta. 2006. Tabel Input Output Sulawesi Utara 2005. BPS dan BAPPEDA Propinsi Sulawesi Utara. CV. Sarah Offset. Sulawesi Utara. 232 hal
2004. Tabel Input-Output Indonesia 2000. Jilid I, II dan III. Badan Pusat Statitstik. Jakarta.

Antara, M. Keterkaitan Usaha Kecil Sektor Pariwisata dengan Sektor-Sektor Ekonomi Lainnya di Provinsai Bali: Suatu Pendekatan Model Input-Output. Jurusan Sosial Ekonomi Pertanian. Fakultas Pertanian Universitas Udayana. Bali.

Kuncoro, M. 2006, Metode Kuantitatif : Teori dan Aplikasi Untuk Bisnis dan Ekonomi, UPP AMP YKPN. Yogyakarta

Kusumastanto, T. 2002. Reposisi "Ocean Policy" dalam Pembangunan Ekonomi Indonesia di Era Otonomi Daerah. Orasi IImiah Guru Besar Tetap Bidang IImu Perikanan dan Kelautan. IPB. Bogor.

Nazara, S. 1997, Analisis Input-Output, Lembaga Penerbit Fakultas Ekonomi Universitas Indonesia. Jakarta.

Priyarsono, D.S, Sahara, M. Firdaus. 2007. Ekonomi Regional. Cetakan 1. Universitas Terbuka. Jakarta

Tajerin, Yusuf, R., Sastrawidjaja dan Asnawi. 2007. Keterkaitan Sektor Perikanan dalam Perekonomian Indonesia Periode 1990-2000: Pendekatan Model Input Output. Badan Riset Kelautan dan Perikanan. Departemen Kelautan dan Perikanan. Jakarta. 